\title{
Mechanical behaviour of polyethylene terephthalate \& polyethylene naphthalate fibres under cyclic loading
}

\author{
C. Lechat ${ }^{1 *}$, A. R. Bunsell ${ }^{1}$, P. Davies ${ }^{2}$ and A. Piant ${ }^{1}$
}

(1) Ecole Nationale Supérieure des Mines de Paris, Centre des Matériaux, BP 87, Evry Cedex, 91003, France

(2) Materials \& Structures group, IFREMER, BP 70, Plouzané, 29280, France

*: Corresponding author : celine.lechat@mat.ensmp.fr

\begin{abstract}
:
Polyethylene naphthalate (PEN) fibres possess a higher initial stiffness than that of polyethylene terephthalate (PET) fibres and this makes them an attractive competitor for use in mooring ropes and other applications for which a low compliance would be an advantage. The two types of fibres have been characterised and compared in tension, creep and fatigue and found to behave in very similar ways. Failure of both fibres results in similar fracture morphologies although under high cyclic loading a new failure process has been observed for the PEN fibres which combines step by step crack propagation and final failure normal to the fibre axis. In the light of this observation, similar fracture behaviour has also been identified in PET fibres and which, until now had been overlooked. The loading criteria for fatigue failure are similar for both fibres and it has been shown that, for a given maximum cyclic load, lifetime is raised if the minimum cyclic load is increased.
\end{abstract}




\title{
Mechanical behaviour of Polyethylene Terephthalate \& Polyethylene Naphthalate fibres under cyclic loading
}

\author{
C. LECHAT *, A. R. BUNSELL \\ Ecole Nationale Supérieure des Mines de Paris, Centre des Matériaux, BP 87, 91003 Evry cedex, France. \\ E-mail : celine.lechat@mat.ensmp.fr \\ P. DAVIES \\ Materials \& Structures group, IFREMER, BP 70, 29280 Plouzané, France.
}

A. PIANT

Ecole Nationale Supérieure des Mines de Paris, Centre des Matériaux, BP 87, 91003 Evry cedex, France.

*Author to whom all correspondence should be addressed.

Polyethylene naphthalate (PEN) fibres possess a higher initial stiffness than that of polyethylene terephthalate (PET) fibres and this makes them an attractive competitor for use in mooring ropes and other applications for which a low compliance would be an advantage. The two types of fibres have been characterised and compared in tension, creep and fatigue and found to behave in very similar ways. Failure of both fibres results in similar fracture morphologies although under high cyclic loading a new failure process has been observed for the PEN fibres which combines step by step crack propagation and final failure normal to the fibre axis. In the light of this observation, similar fracture behaviour has also been identified in PET fibres and which, until now had been overlooked. The loading criteria for fatigue failure are similar for both fibres and it has been shown that, for a given maximum cyclic load, lifetime is raised if the minimum cyclic load is increased.

\section{Introduction}

Polyethylene terephthalate (PET, commonly known as polyester) fibres, are the most widely produced synthetic organic fibres and together with polyamide (nylon) fibres make up the great majority of synthetic fibres produced. They are used both for traditional textile purposes and increasingly for industrial applications. It is their use in industrial applications which is of concern in the present paper. Such applications include the reinforcement for rubber, as in tyres and belting, and in ropes and cables. The market for the latter application is increasing rapidly as, particularly, PET cables find use in mooring ropes for boats, especially large ships such as oil tankers and for the mooring cables for off-shore oil platforms [1,2]. Such cables have breaking loads of up to two thousand tons and consist of many millions of fine synthetic fibres. Fibres destined for these applications are generally more highly drawn than fibres for use in traditional textile structures and this leads to higher strength and stiffness combined with a reduced strain to failure. The interest in the use of synthetic fibre cables for oil platforms has increased as drilling is performed in ever deeper seas so that now depths of up to $3000 \mathrm{~m}$ are being envisaged. Synthetic fibres are much lighter than traditional steel cables or chains and this is appreciated at all stages of their transport and manipulation as well as reducing the drag on the platforms which allows greater weight of on board equipment to be envisaged. Lifetimes which are required for these cables are of the order of twenty years during which they are subjected to high loads which vary continuously due to the sea and weather conditions. Failure must be avoided as it would endanger lives, make the platform unstable and stop oil production. The fibres, which are not elastic, inevitably undergo changes due to the imposed loads so that creep and possibly other deformation and failure processes have to be understood if their use is to broaden. 


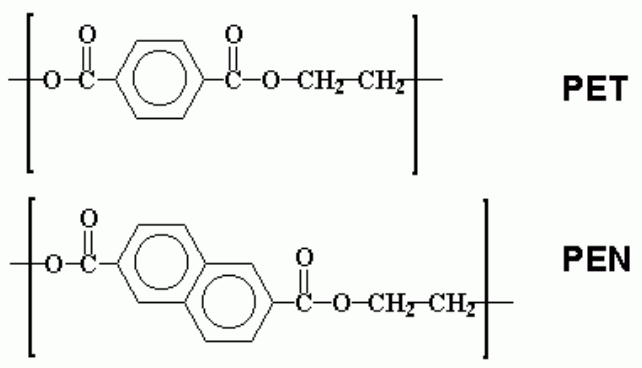

Figure 1 Molecular structures of polyethylene terephthalate \& polyethylene naphthalate.

Polyamide (PA) fibres, with respect to PET fibres, find fewer applications, in the types of structures which are under consideration, as the former fibres absorb a considerable amount of water which leads to significant changes in properties. PET fibres absorb little water due to their non-polar molecular structure. In addition the molecular structure of PET contains an aromatic ring whilst PA has an aliphatic, linear structure. The result is that PET fibres can be stiffer than PA fibres, which is clearly an advantage with very long structures as deformations can be considerable if the compliance is high. For the same reason polyethylene naphthalate (PEN) fibres have attracted attention for use in cables. Fig. 1 compares the molecular structures of PET and PEN and it can be seen that the latter fibre possesses two aromatic rings in its molecular structure. The increase in rigidity which this structure confers on the molecule is translated to the properties of the fibres which are produced so that PEN fibres can be up to twice as stiff as PET fibres [3]. These properties are desirable in cables so that PEN fibres are candidates for such uses.

The loading patterns to which mooring cables are subjected over their lifetimes will determine their ultimate behaviour and possible failure. This behaviour is determined largely by the behaviours of the constituent fibres together with other effects, such as abrasion, which are induced by the structure of the cable. The mechanisms which cause the failure of fibres will determine the ultimate lifetimes of the cables. Failure of individual fibres can be due to simple monotonic tensile forces exceeding the breaking strength of a fibre, creep, which leads to failure, after a delay, at loads lower than that which produces simple tensile failure or fatigue failure, which is due to the cyclic nature of the loading pattern. The effect of the loading pattern on the fatigue behaviour has previously been studied for several types of fibres but not for PEN fibres $[2,4-7]$. The loading history of the fibres making up the cables and which is due to the platform motion and wave loading, has been simplified for the purposes of this study to one of a sinusoidal load superimposed onto a steady tensile load.

It has been seen that the fracture morphologies of broken fibres can be used to diagnose the nature of the failure and previous studies [4-9] have shown that several kinds of fibres, including PA and PET fibres, subjected to cyclic loading fail with a fracture process which is distinctive from that seen in tensile or creep failure. The tensile or creep failure of such fibres shows two distinct stages, as can be seen from Fig. 2a:

- Initiation on (or near) the surface of the fibre, followed by slow crack growth normal to the fibre axis with plastic deformation leading to crack opening ("V-crack"),

- Catastrophic failure of the remaining transverse section.

Under certain cyclic loading conditions, a quite different morphology has been observed with both nylon and polyester fibres (Fig. 2b):

- Initiation at or near the surface of the fibre,

- Sharp deviation of the crack so that it propagates at a very slight angle to the fibre axis.

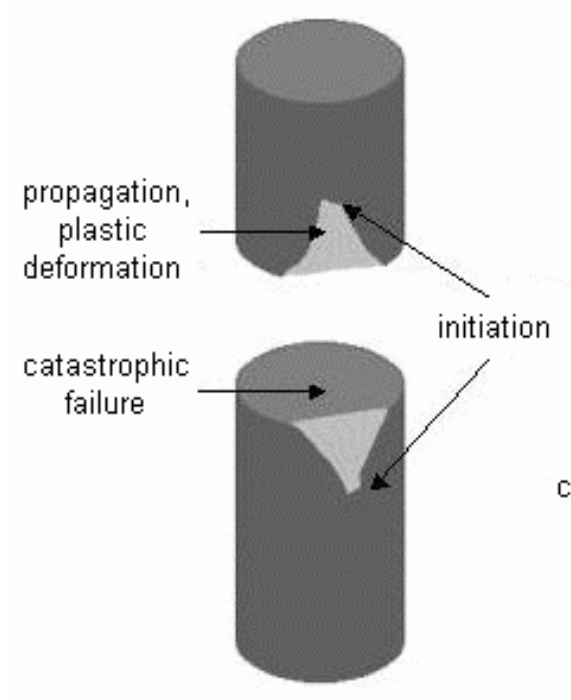

a) tensile / creep failure

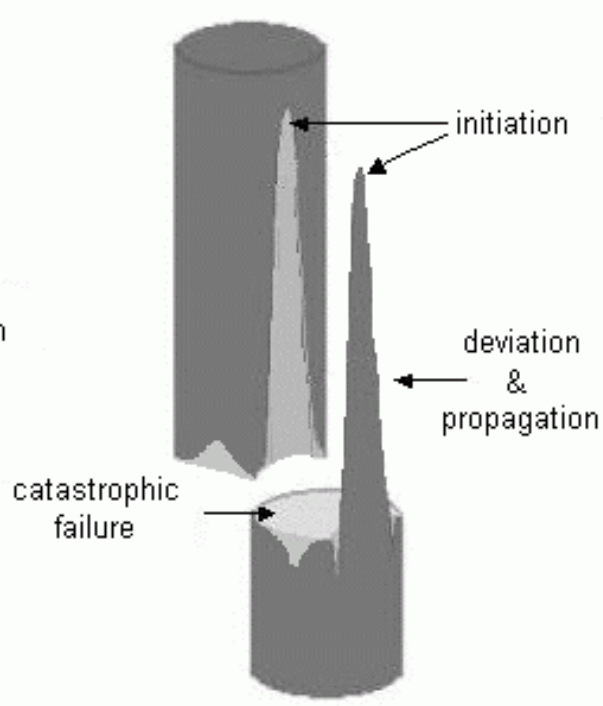

b) fatigue failure

Figure 2 Typical fracture morphologies of PET \& PA fibres after tensile or creep failure and after fatigue failure. 
- Propagation of the crack, resulting in a reduction of the load-bearing section and the creation of a detached "tongue of material".

Failure occurring by the creep process when the section becomes too small to bear the maximum applied cyclic stress. From this point, the final failure steps involve propagation normal to the fibre axis and look similar to the two stages of tensile failure.

This latter type of failure, which only occurs under cyclic loading, is defined as a fatigue failure [7]. Such failures have been seen to occur if the cyclic load amplitude is sufficiently large and if the minimum load is lower than a threshold level which is generally considered to be around $10 \%$ of the breaking load.

Many characteristics of fibres are being continuously improved as research and manufacturing processes evolve [3,10-15]. Recent studies on PA fibres have shown that the conditions for fatigue failure in high performance fibres produced in the last few years have been modified, no doubt due to changes in molecular morphology [4]. As cyclic loading occurs in many applications, it has become necessary to reexamine the conditions under which fatigue occurs in PET fibres and to examine the fatigue behaviour of PEN fibres, in the light of their potential use in applications such as mooring ropes and tyre cords [3]. Apart from some standard characteristics, there exist few data for the recently developed PEN fibre [3,10,11,13-16]. In particular no fatigue data has been published.

This paper describes mechanical testing (tensile and cyclic loading) on PEN and PET fibres, both produced for offshore application. A comparison is made between the fibre fracture morphologies observed with SEM, and also results from previous studies on PET and PA fibres, in order to determine the mechanisms leading to failure.

\section{Experimental details}

\subsection{Materials}

The fibres which have been tested in this study were extracted from highly drawn PEN and PET multifilaments. PEN fibres were provided as 1100dtex yarns, one yarn containing 140 fibres, each fibre having an average diameter of $28( \pm 2) \mu \mathrm{m}$. PET fibres were provided as 1100dtex yarns, one yarn containing 192 fibres, each fibre having an average diameter of 23 $( \pm 2) \mu \mathrm{m}$. Both types of fibre were seen to be cylindrical with the SEM.

The molecular structures of both polymers are shown on Fig. 1. They are similar, but the naphthalene ring in $P E N$ replacing the benzene ring in $\mathrm{PET}$ should confer a higher stiffness to the structure.

For mechanical testing, single fibres (= monofilament) were extracted from the yarn. Each fibre was held at both ends in small cardboard tabs pasted with neoprene glue, the length between tabs being $50 \mathrm{~mm}$ and corresponding to the gauge length.

\subsection{Diameter Measurement}

An initial study by scanning electron microscopy revealed that the diameter of any one fibre did not significantly change along its length. A calibrated Mitutoyo LS 6000 Laser with 0,1 $\mu \mathrm{m}$ precision was used to determine diameters before each test. The whole length of each tested fibre was examined and the smallest diameter measured was used for calculating the characteristics of the fibre as any larger values were taken to be due to dust particles on the fibre surface.

\subsection{Tensile - Creep tests}

Tensile and creep tests in the fibre direction were conducted with an apparatus called the Universal Fibre Tester [17]. This device consists of two clamps, one being directly fixed on the frame, and the other on a mobile cross-head. The cross-head displacement, thus the distance between clamps, is controlled by an electric motor and measured to within $1 \mu \mathrm{m}$ with a LVDT transducer. A constant load or constant displacement or a computer controlled loading pattern could be imposed on the fibre. The displacement speed was chosen by the operator, and in this study, was held to be $10 \mathrm{~mm} / \mathrm{min}$. The load applied to the fibre was measured by a load cell $(0.01 \mathrm{~g}$ sensitivity). Load and displacement data were then collected using a standard software package (winATS), and treated in order to obtain stress and strain data.

\subsection{Cyclic loading tests}

In order to apply a sinusoidal cyclic load to fibres, the machine described in the previous paragraph was equipped with a vibrator, operating on the same principles as a loud speaker. This allowed the operator to choose the minimum and the maximum values of the cyclic load. These values are expressed as a percentage of the mean breaking stress determined by the tensile tests. A servo system permitted the machine to compensate for creep and preserve exactly the same sinusoidal load throughout the test. The main data obtained through this test were the number of cycles to failure. The tests were run at $50 \mathrm{~Hz}$.

All the mechanical tests were carried out at a constant temperature of $21^{\circ} \mathrm{C}$ and relative humidity of $50 \%$. Only fibre failures occurring in the gauge length were considered and failures in the grips were discounted.

\subsection{Scanning Electron Microscopy (SEM)}

Fracture morphologies of the fibres were observed with a Gemini 982 Zeiss microscope fitted with a field effect gun which allows studies to be performed at low accelerating voltages. For this study a voltage of $2 \mathrm{kV}$ was used. The fibres were however coated with gold palladium to avoid any possible problem of charging. The complementary ends of broken fibres were examined.

\section{Results}

\subsection{Fibre dimensions}

The scatter in fibre diameters for both types of fibres was determined. Fig. 3 represents the distribution of 


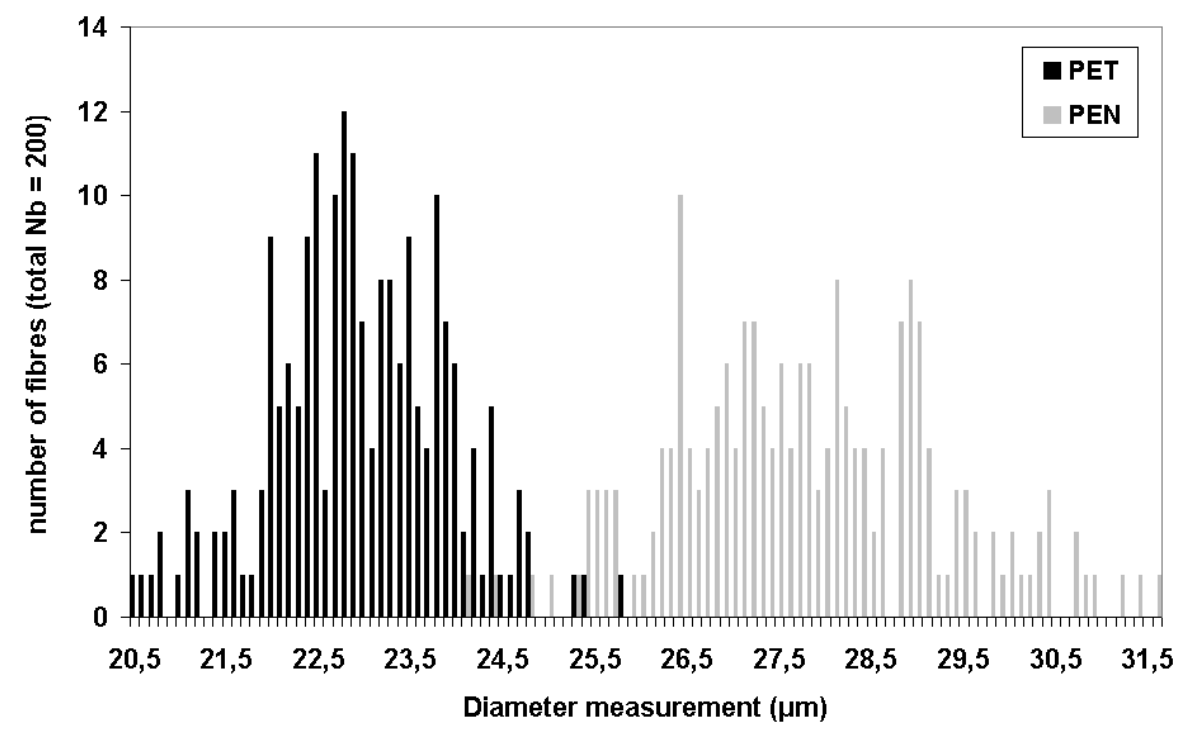

Figure 3 Diameters distribution, PET \& PEN fibres (200 measurements for each type of fibre).

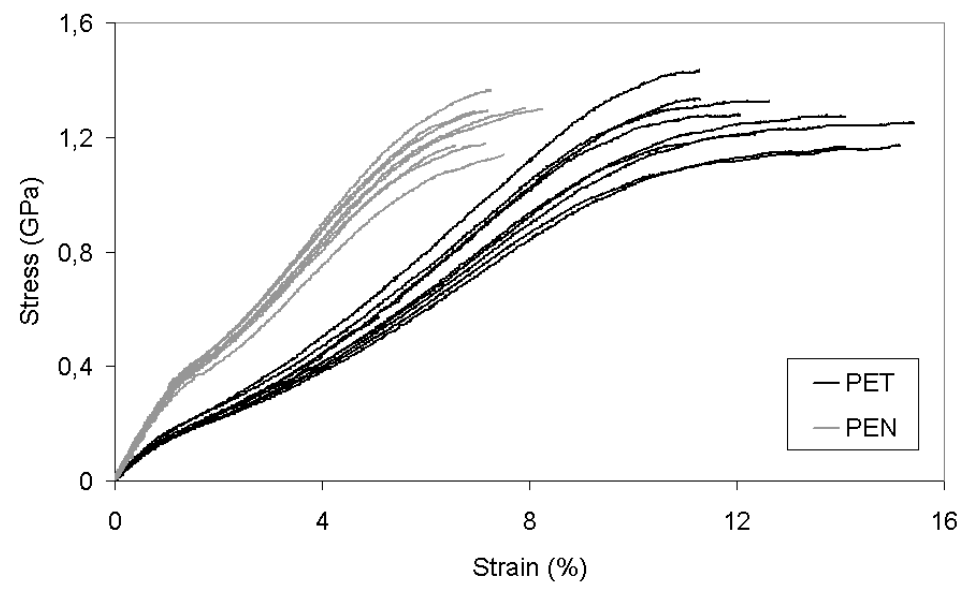

Figure 4 Stress-strain curves from tensile tests, PET \& PEN single fibres.

fibre diameters for 200 measurements, for each type of fibre. It shows that there was a wide range of diameters for each type of fibre. This scatter in diameter accounts for scatter in the values of the measured properties.

\subsection{Tensile tests}

Stress-strain curves for single PET and PEN fibres are shown in Fig. 4, and reveal the scatter in behaviour. The average values of mechanical characteristics were calculated from the results of 10 samples and are given in Table I. The initial modulus is defined as the slope of the stress-strain curve between zero and $1 \%$ strain. In view of similar studies on other grades of PET [4,5], the results obtained for PET fibres were expected : the characteristics values and shape of tensile curves are typical of PET fibres in general. The PEN fibres were found to show very similar failure stresses to those of the PET fibres but their moduli were found to be twice as high.

\subsection{Creep tests}

Creep tests were conducted so as to compare average lifetimes with those obtained under cyclic conditions. As fibres subjected to cyclic loads spend only a small fraction of each cycle at the maximum load, lifetimes should be considerably longer than those recorded for steady loads at the level of the maximum cyclic load, if

TABLE I Main mechanical characteristics values for PET and PEN single fibres, compared to values from literature [5].

\begin{tabular}{cccc}
\hline Characteristic & $\begin{array}{c}\text { PET } \\
(@ 20 \% / m i n)\end{array}$ & $\begin{array}{c}\text { PEN } \\
(@ 20 \% / m i n)\end{array}$ & $\begin{array}{c}\text { PET 1 [5] } \\
(@ \mathbf{4 0} \% / \text { min })\end{array}$ \\
\hline $\begin{array}{c}\text { Breaking Stress } \\
(\mathrm{GPa})\end{array}$ & $1.26 \pm 0.1$ & $1.25 \pm 0.1$ & 0.96 \\
\hline $\begin{array}{c}\text { Breaking Strain } \\
(\%)\end{array}$ & $13 \pm 2$ & $7 \pm 1$ & $15.4 \pm 2.2$ \\
\hline $\begin{array}{c}\text { Initial Modulus } \\
(\mathrm{GPa})\end{array}$ & $13 \pm 2$ & $26 \pm 1$ & - \\
\hline
\end{tabular}



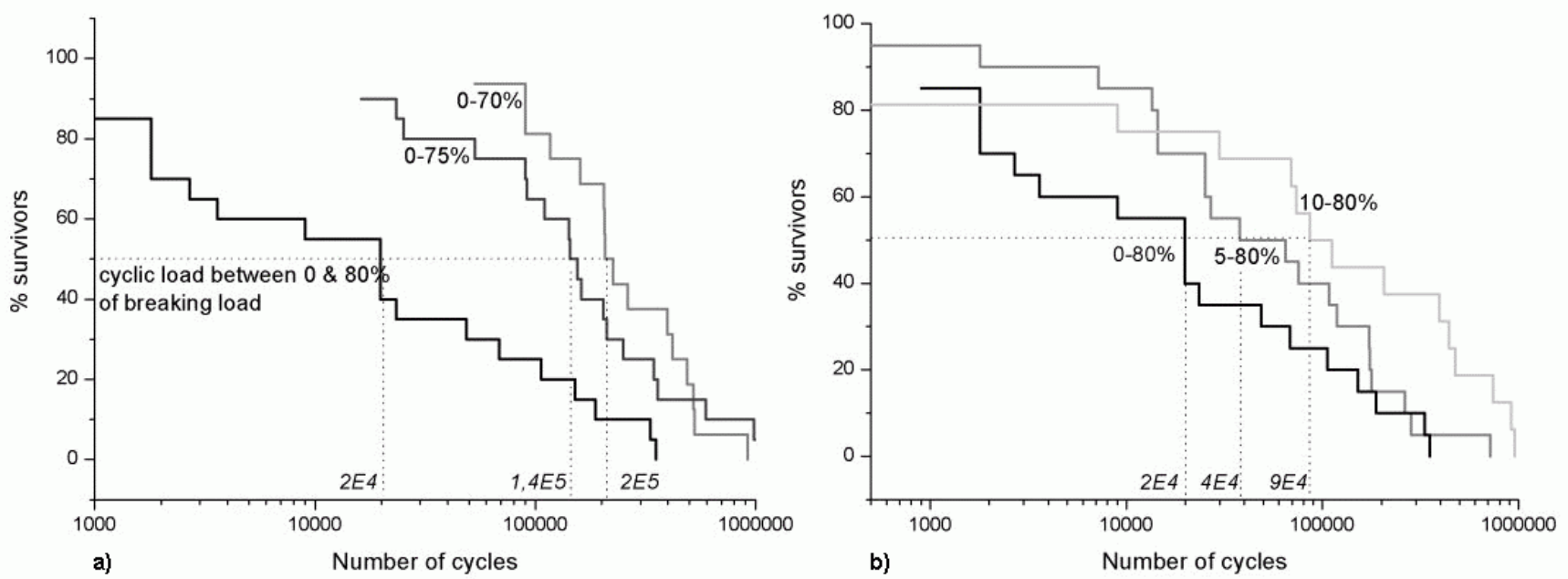

Figure 5 Lifetime data for PET fibres after different cyclic loadings.
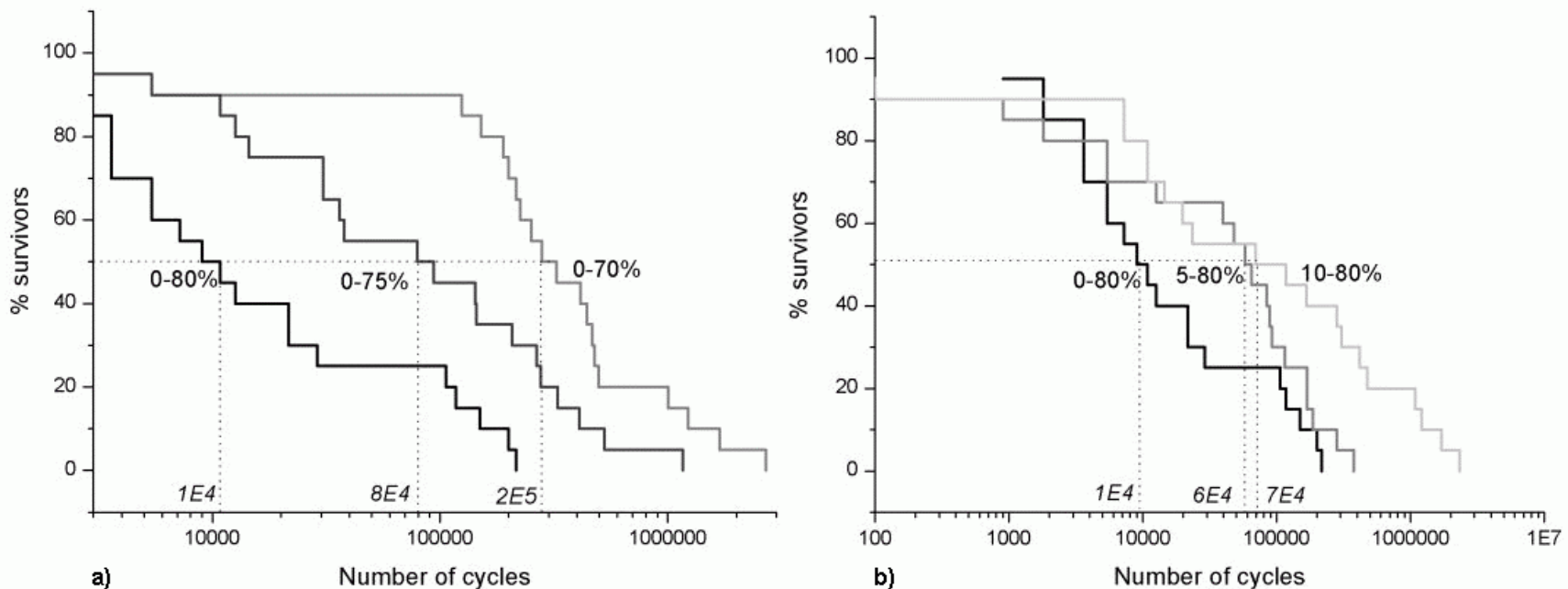

Figure 6 Lifetime data for PEN fibres after different cyclic loadings.

it were the creep process which controlled failure. The fibre was held at $70 \%$ breaking load. Two fibres of each type were tested under these conditions and for both the PET and PEN fibres survived steady loading for $100,000 \mathrm{~s}$, equivalent to $5 \times 10^{6}$ cycles of fatigue. At this point the tests were stopped. This result will be compared to cyclic loading results later in the discussion.

\subsection{Cyclic loading tests}

Different values of cyclic load were applied to single fibres. For each cyclic loading pattern, a large number of fibres were tested, as there was a significant scatter in lifetimes recorded. This can be seen from Fig. 5 which represents the percentage of non-broken fibres as a function of the number of cycles applied to the fibres. The different sinusoidal loads applied were : 1 ) between 0 and $70 \%$ of breaking stress, 2) between 0 and $75 \%, 3$ ) between 0 and $80 \%$. Beyond this maximum value, fibres broke within a few seconds from the tensile or creep processes. It can be seen from Fig. 5a that with a zero minimum load, an increasing maximum load resulted in a reduction of the lifetime of PET fibres. As expected, the maximum load had a strong influence on lifetimes; these results confirmed previous observations [4,5]. Other loading conditions were also applied : 4) from 5 to $80 \%$ of the breaking stress ; 5) from 10 to $80 \%$ (cf. Fig. 5b). These results also agreed with previous studies [4,5]: the increase in minimum load resulted in an increase in lifetime. As with the PET fibre specimens the results obtained with the PEN fibres showed that the minimum load as well as the maximum load influenced lifetime (cf. Fig. 6). The behaviour of the two types of fibres subjected to cyclic loads seemed very similar. The median lifetimes of the PET and PEN fibres, when subjected to three different maximum cyclic loads but each with zero minimum loads are compared in Table II. The median lifetimes of both types of fibres, cyclically loaded to $80 \%$ of the mean breaking load, but with different minimum loads, are shown in Table III. 
Table II Median lifetimes of fibres subjected to cyclic loading at $50 \mathrm{~Hz}$, with a zero minimum load and different maximum loads expressed as a percentage of the mean breaking load, compared to values from literature [5]

\begin{tabular}{lccc}
\hline Maximum load & PET & PEN & PET 1 [5] \\
\hline $80 \%$ & $2 \times 10^{4}$ & $1 \times 10^{4}$ & - \\
\hline $75 \%$ & $1 \times 10^{5}$ & $8 \times 10^{4}$ & - \\
\hline $70 \%$ & $2 \times 10^{5}$ & $2 \times 10^{5}$ & $1 \times 10^{5}$ \\
\hline
\end{tabular}

Table III Median lifetimes of both types of fibres cyclically loaded at $50 \mathrm{~Hz}$ to $80 \%$ of average breaking load, with different minimum loads

\begin{tabular}{lll}
\hline Minimum load & PET & PEN \\
\hline $0 \%$ & $2 \times 10^{4}$ & $1 \times 10^{4}$ \\
\hline $5 \%$ & $4 \times 10^{4}$ & $6 \times 10^{4}$ \\
\hline $10 \%$ & $9 \times 10^{4}$ & $7 \times 10^{4}$ \\
\hline
\end{tabular}

\subsection{Fracture morphologies}

Scanning Electron Microscopy studies revealed the two main fracture morphologies existing for PET fibres [5]. Tensile morphologies were found to be similar to those shown in Fig.2a. It should be noted that the roughness of the initial stage of propagation is normal to the boundary between the two stages of crack propagation. As can be seen from fig. 7, the failure after cyclic loading (in this case $0-80 \%$ loading, 117,000 cycles lifetime) can lead to a typical fatigue morphology, with a "tongue" of material showing the angle of crack propagation (right side picture) and the corresponding groove on the other part of the broken fibre (left side picture). Nevertheless, cyclic loading should not be automatically associated with fatigue failure, as seen from Fig. 8 which shows complementary broken ends of a PET fibre, broken after cyclic loading between 0 and $80 \%$ of the breaking load. This morphology looks exactly similar to creep or tensile failure morphologies found for these types of fibres. The creep and fatigue processes have to be seen as being in competition so that under maximum cyclic loads which are very high fractions of the breaking load, creep failures can be observed. However a closer inspection of such creep failure revealed two distinctive types of morphologies. In some cases the failure morphology is identical to that seen in static load creep tests. However, for the majority of the PEN fibres broken under cyclic loading, the roughness of the first stage of failure was seen to consist of steps in the crack propagation, as discussed below. This led to a re-examination of the fracture morphologies of cyclically loaded PET fibres which failed, apparently by
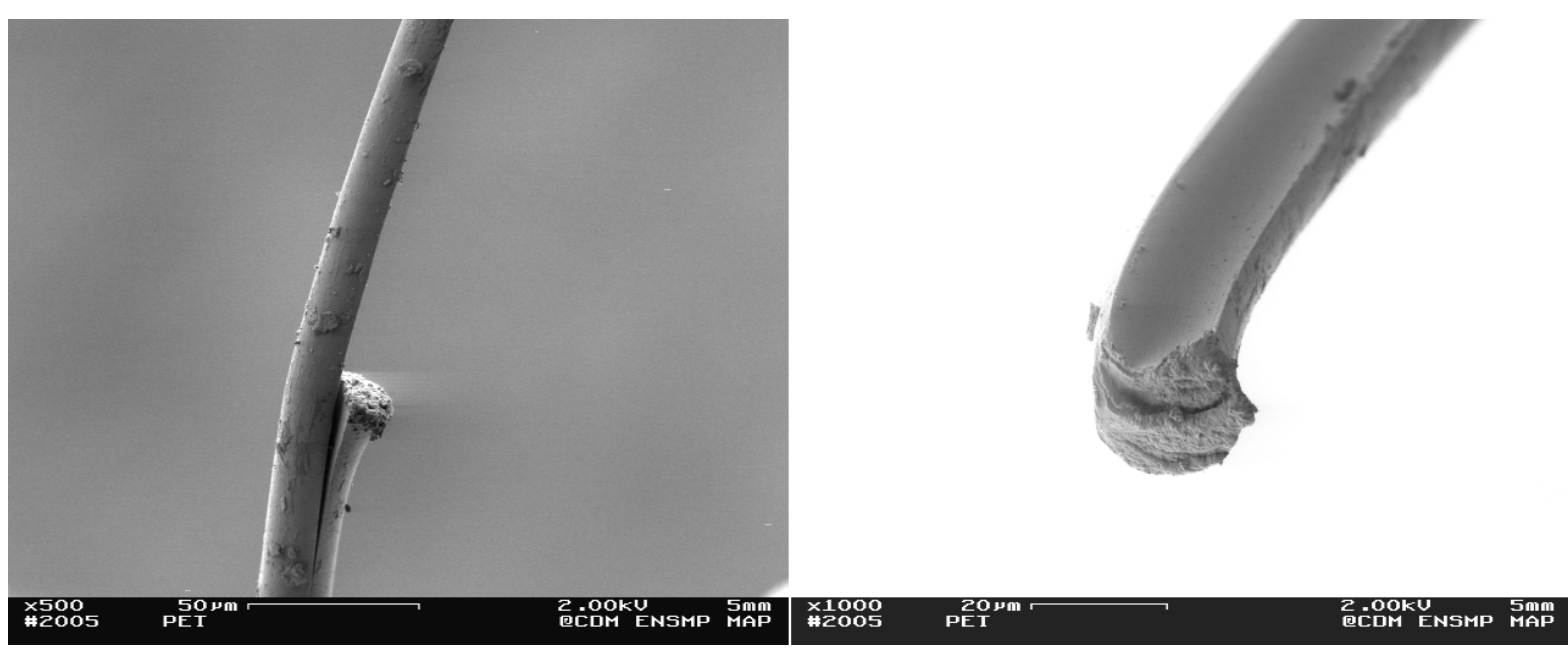

Figure 7 Complementary failure morphologies, PET fibre, fatigue failure $(0-80 \%)$, lifetime $=1.105$ cycles. The tongue of material (on the left side picture) has stripped off the upper side of the other part of the fibre (right side picture), leaving a corresponding hollow.

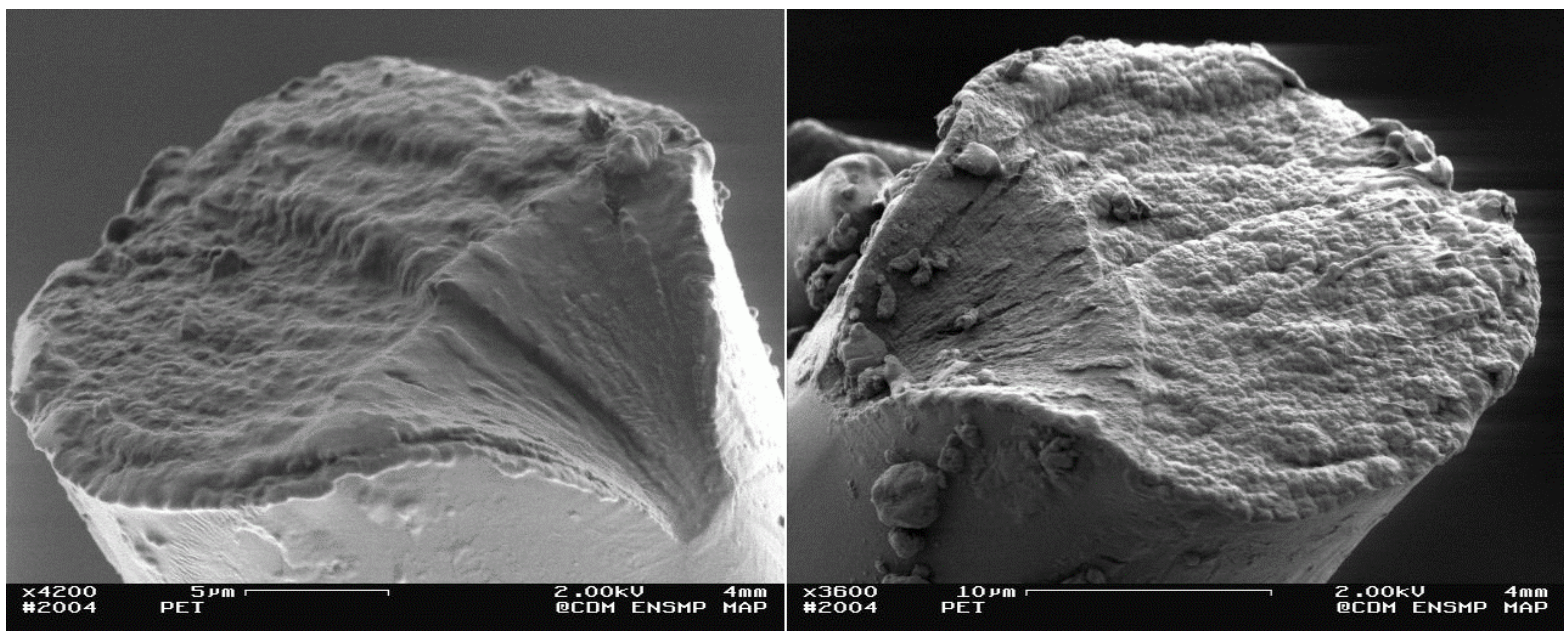

Figure 8 Complementary failure morphologies, PET fibre, cyclic loading $(0-80 \%)$, lifetime $=2.103$ cycles. The morphology is similar to what was previously found for tensile failures. 


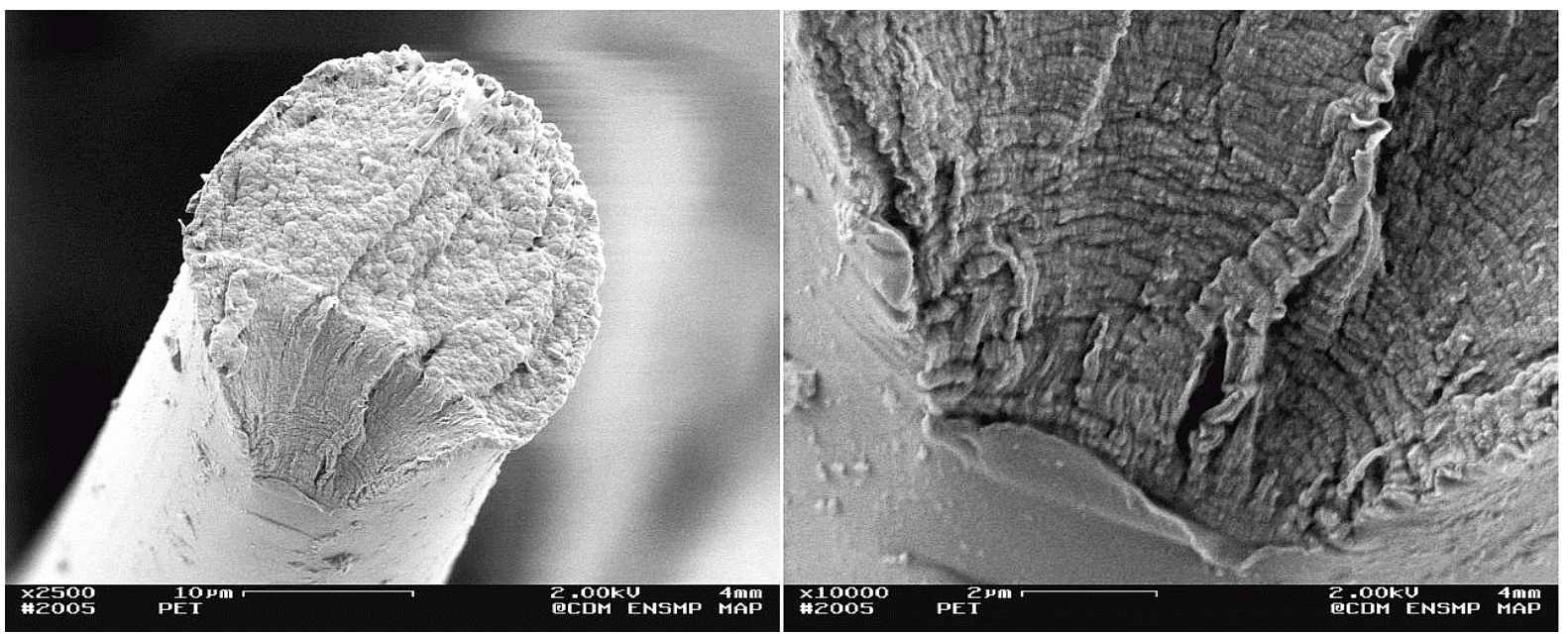

Figure 9 Failure morphology, PET fibre, cyclic loading (0-80\%), lifetime $=2.104$ cycles. At first sight the morphology is similar to that in Fig. 8 , but a closer view of the initiation zone (right side picture) shows striations normal to the crack propagation axis.

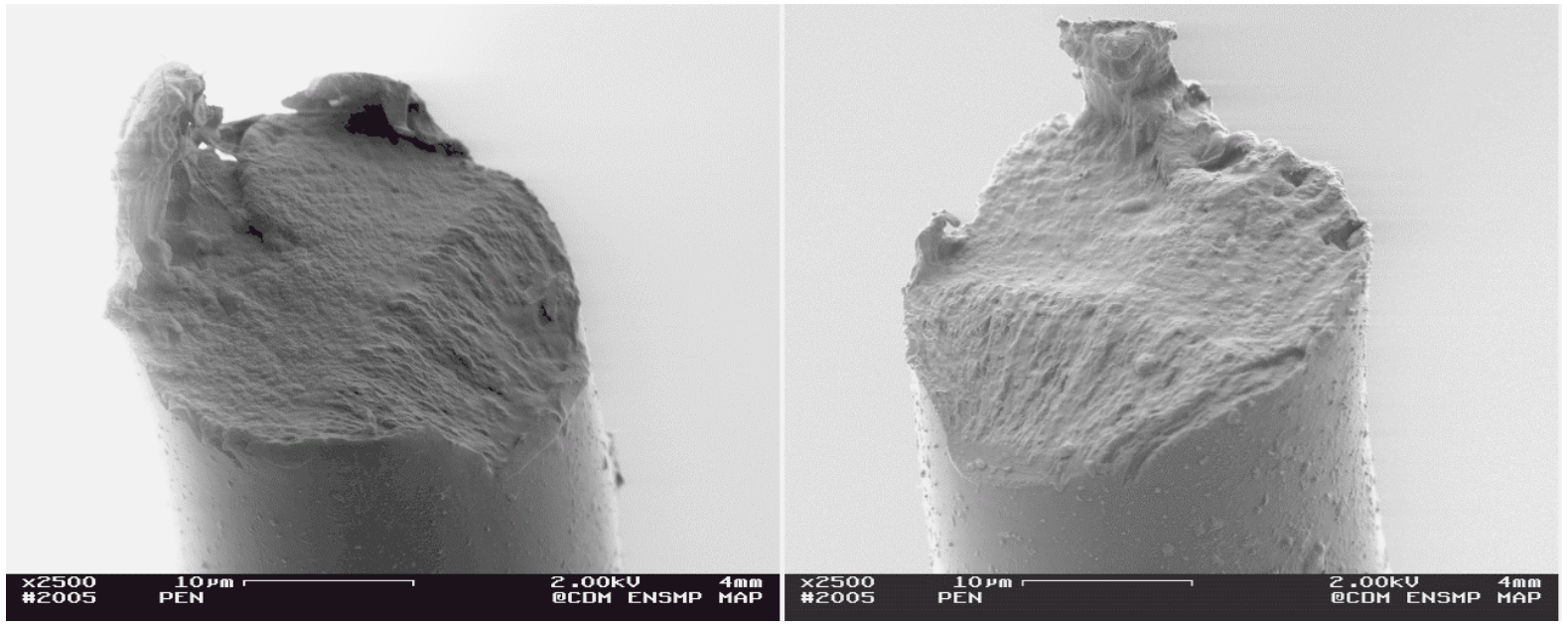

Figure 10 Complementary failure morphologies, PEN fibre, tensile failure.

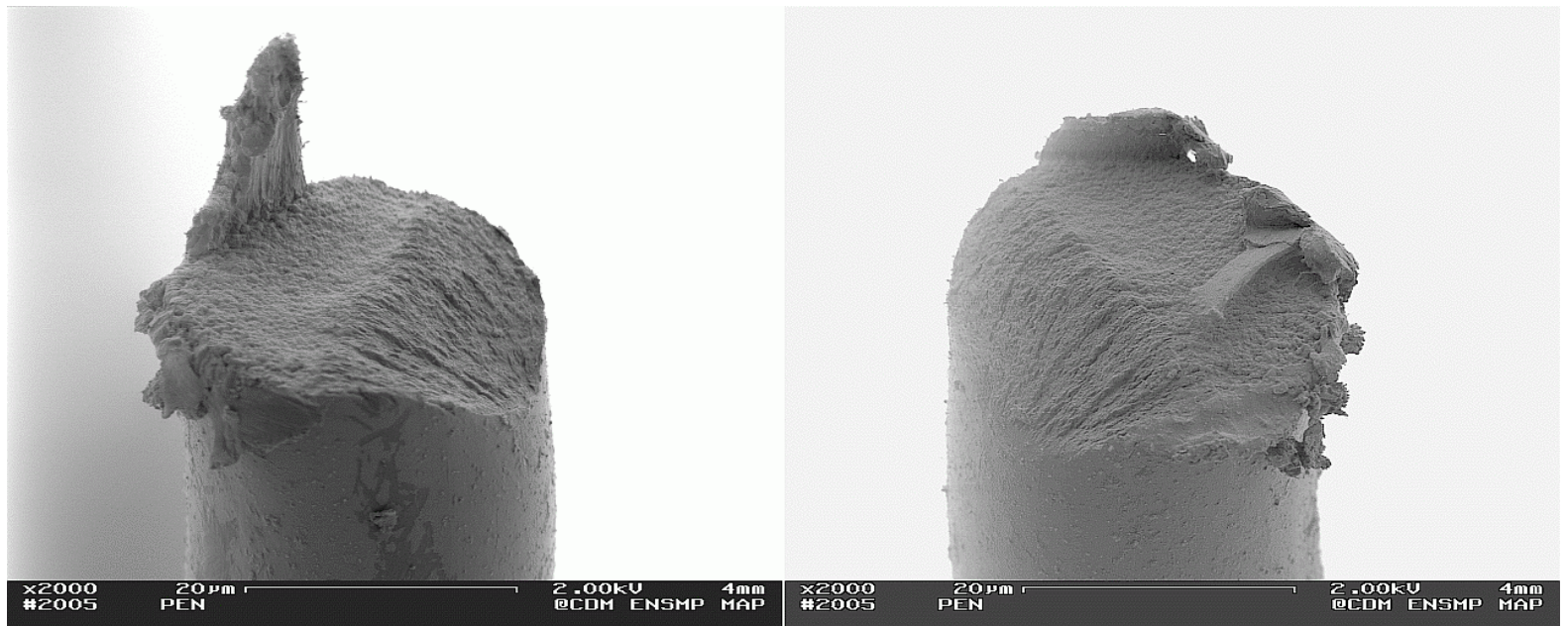

Figure 11 Complementary failure morphologies, PEN fibre, creep failure (85\%).

creep. Fig. 9 shows that, although the striations are not very distinct, there is clear evidence on the enlarged view of the first stage of failure (right side of picture) of step by step crack propagation parallel to the boundary between the two stages of crack propagation.

Figs. 10 and 11 show, respectively, typical tensile and creep failure morphologies for PEN fibres. They appear similar to that found with PET fibres. Fatigue failure was also found to exist for PEN fibres subjected to cyclic loads, as can be seen from Fig. 12. The crack deviation and long tail observed with PET fibres and also PA fibres are again a notable feature of the fatigue of PEN fibres. As indicated above, the step by step propagation process newly identified in the PEN fibres is much more marked than in the PET fibres, as can be seen in Fig. 13 a\&b. Two distinctive zones of tensile or 

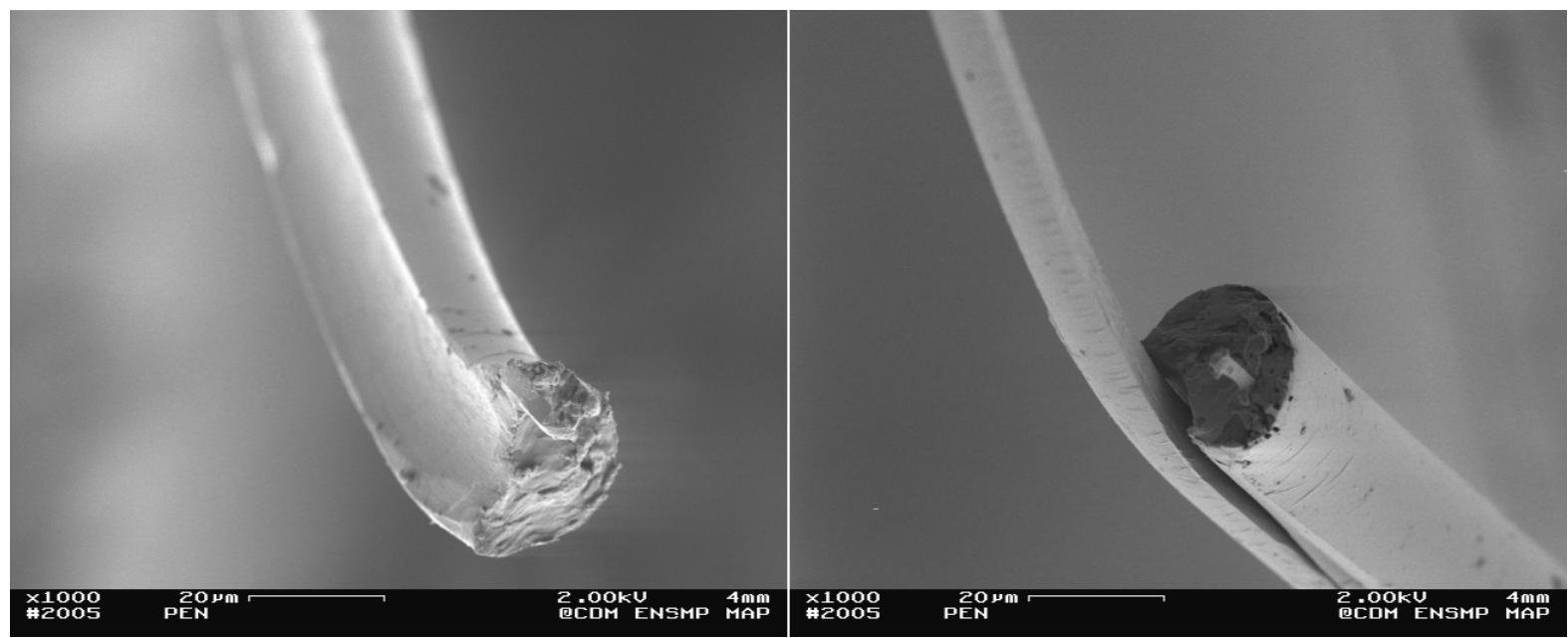

Figure 12 Complementary failure morphologies, PEN fibre, fatigue failure $(0-75 \%)$, lifetime $=3.105$ cycles. The failure mechanism is similar to that described in Fig.7.
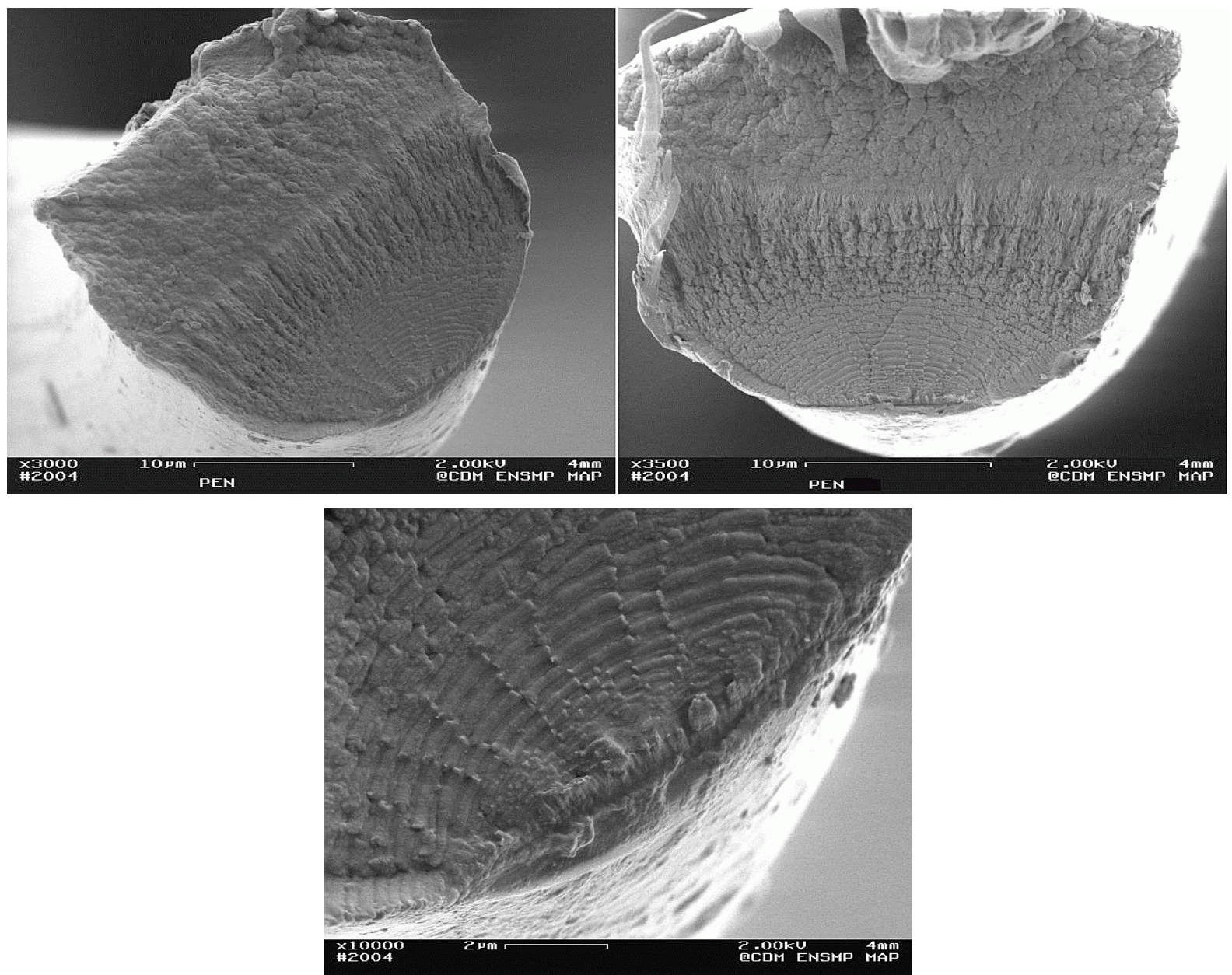

Figure 13 (top) Complementary striated failure morphologies, PEN fibre, cyclic loading (0-80\%), lifetime $=3.104$ cycles (bottom) Closer view of the striated zone on the bottom left picture.

creep crack propagation were observed and no crack deviation along the fibre was seen. However, closer examination of these figures reveals that regular striations can be observed in the slow crack zone of the failure morphology, due to distinct steps in the crack advance under the imposed cyclic conditions.

\subsection{Stress calculations - another approach}

During cyclic loading tests, all the applied stress values had been calculated as a percentage of an average breaking stress. This average value was calculated from all the breaking load values obtained during tensile tests, taking into account the diameter of each fibre. The effect of the fibre diameter on its strength was examined in detail and as can be seen from Fig. 14 , it was shown that breaking stress can be defined as a linear function of the fibre diameter. Tensile tests were carried out with a longer gauge length $(100 \mathrm{~mm}$ instead of $50 \mathrm{~mm}$ ) to determine if the loss in breaking stress was due to an increase in diameter, external 


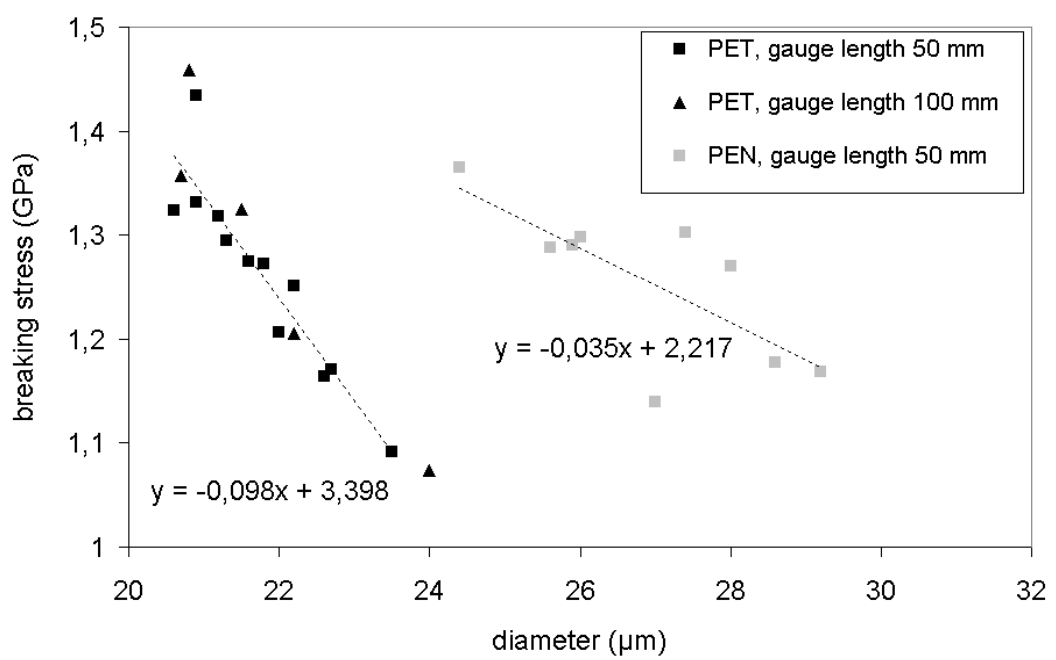

Figure 14 Relation between breaking stress and diameter for PET \& PEN single fibres.

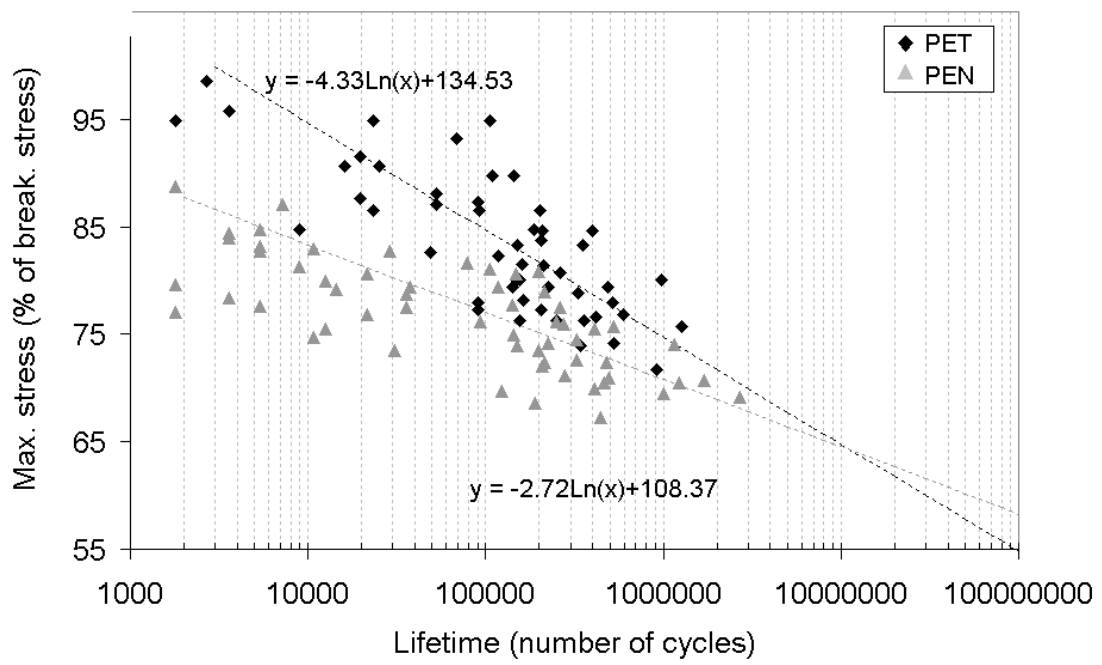

Figure 15 SN curves for PET \& PEN fibres after cyclic loading with a zero minimum load and various maximum loads.

surface or total volume of the sample. Fig. 14 shows that the determining factor was the diameter. As a consequence, the breaking stresses evaluated for each fibre subjected to fatigue loading were revised for each tested fibre. In this way, percentages of ultimate failure load evaluated for cyclic loading tests could be determined with more precision. For example, when the maximum applied load was meant to represent $75 \%$ of the breaking load, it could actually be between 73.9 and $90.6 \%$, as a function of the real fibre diameter. Thus a SN curve seems a reasonable manner to present the results as shown in Fig. 15.

\section{Discussion}

\subsection{Tensile results}

The tensile tests results on PET fibres confirm results already published in the literature. The shape of the stress-strain curve has been explained by Herrera [4], based on the microstructural model first advanced by Prevorsek [18], later developed further by Oudet [19] and completed by Marcellan [20-22]. In this model the fibre is considered to be made up of microfibrils, which form its basic structural element. Microfibrils consist of different types of molecular arrangement : crystalline blocks are linked by amorphous areas in the fibre axis direction, the amorphous tie-molecules being isotropic. Microfibrils are aligned along the fibre axis, and cohesion in the transverse direction is made through another type of amorphous phase, preferentially oriented along the fibre axis, and thus called mesamorphous phase. Microfibrils are grouped to form a macrofibril, and several macrofibrils are tied together by a mesamorphous phase (of a lower density than the previous one) to form a fibre (Fig. 16). This model allows the tensile curve to be explained as follows : on initial loading the strain is due to an alignment of the amorphous phases until they reach a preferential orientation similar to the mesamorphous phase (inflexion point of the curve). This anisotropic amorphous phase is then supporting the applied load. From the second inflexion point some bonds are strained in both the aligned amorphous phases and in the crystalline phase. The final part of the curve is due to slippage between macrofibrils.

The variability of tensile properties can be explained as resulting from the production process : during spinning, fibres in the bundle experience slightly different temperatures and drawing conditions due to variations in diameter and their position in the bundle. This is the case for the breaking stress, as discussed earlier, and 


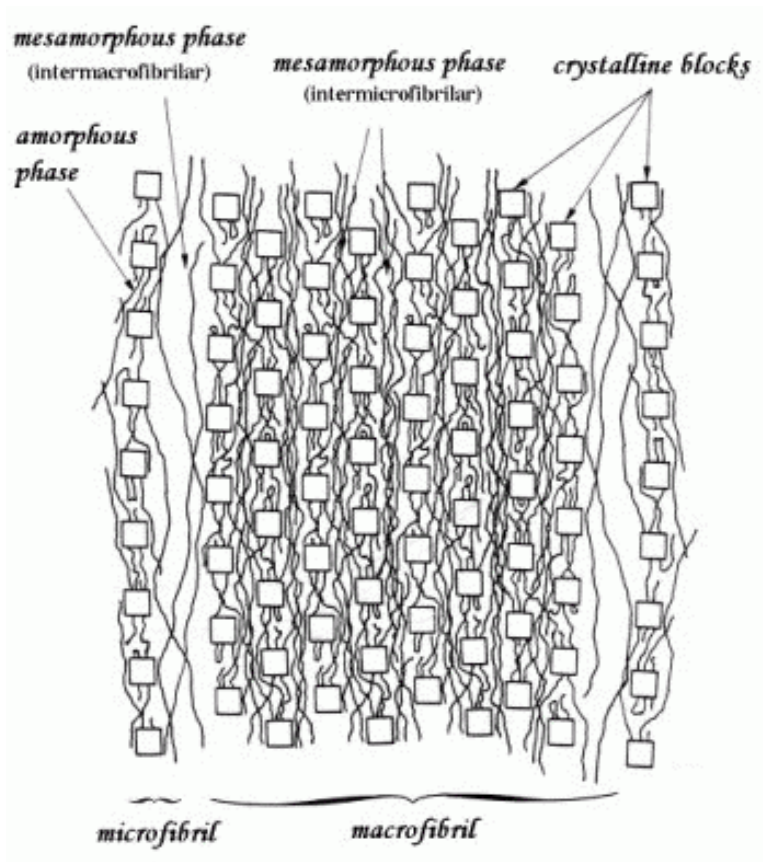

Figure 16 Fibrillar model for PET fibres [19].

a further study showed that it is also true for the breaking strain, which distinctly increases with diameter. In both cases the dependence was much more obvious with PET fibres than with PEN. This could reflect a slight difference in draw ratios within a bundle, and a wider difference in draw ratios of the two fibres' manufacturing processes. A study considering the influence of diameter on true stress could also help to understand this phenomenon.

PEN tensile curves show very similar behaviour to that of PET fibres. Higher stiffness is mainly due to the presence of the naphthalene ring [3]. The oriented amorphous phase was also found to exist in this polymer $[23,24]$. Thus it seems reasonable to apply the Oudet molecular organization model to PEN fibres. Nevertheless some differences can be highlighted by considering the evolution of stiffness during the tensile tests. Fig. 17, which represents average curves of normalised stiffness versus normalised strain, shows that stiffness evolves differently for both fibres. The second part of the curve corresponds to the partial alignment of the amorphous phase, and the slope is much greater for PET than for PEN. This tendency can be explained by the molecular structure of the fibres. The potential of alignment of the molecules is higher in PET fibres, as the PEN molecule is stiffer and allows fewer movements.

\subsection{Cyclic loading and fracture morphology results}

The comparison between creep and cyclic loading lifetimes gives valuable information about failure modes under cyclic loading. If failure under cyclic loading was due entirely to the creep process (progressive increase in fibre length), the fatigue failure should occur later than during a simple creep test at the same load level, as the fibre undergoes the same maximum load for a shorter time. But the results of the fatigue experiments show that this was not the case. Both fibres were subjected to cyclic loadings, from $0 \%$

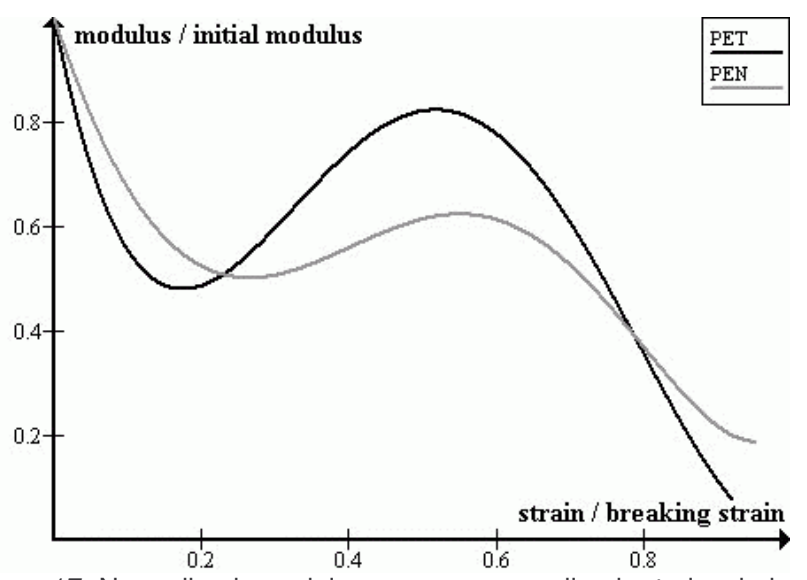

Figure 17 Normalised modulus versus normalised strain during tensile test for PET \& PEN single fibres.

up to $70 \%$ of the monotonic breaking load and the maximum lifetime recorded was 53,000 s, with a median value of $4,000 \mathrm{~s}\left(2.10^{5}\right.$ cycles $)$ whereas the minimum lifetime for creep tests was greater than 100,000 s. This demonstrates, with no equivocation, the existence of a particular fatigue failure mode under cyclic loading, confirmed by the tongue and groove fracture morphology : the typical fatigue morphology with long crack propagation was observed in many cases.

The influence of minimum and maximum applied load on lifetime has already been discussed $[4,5]$ for two different types of polyester fibres, and this tendency is confirmed here for another PET fibre, and moreover for the PEN fibre.

In order to compare both fibres, the median lifetime (number of cycles for which $50 \%$ of the fibres are broken) is a relevant parameter. For each loading pattern, the median lifetimes of both fibres are quite similar, as shown in Tables $2 \& 3$. Median lifetime value for $0-70 \%$ load can also be compared to published results for another PET fibre tested previously [5] (tensile properties for this fiber are also given in Table 1). For both fibres (PET and PEN), median lifetime showed to be twice as long as the other PET fibre considered in the literature (Table 2). The differences may be due to differences in fibre manufacture and processing parameters such as the increase in spinning speed. Another way to compare PEN and PET performances after cyclic loading is to consider SN curves. Both can be fitted with a log curve (cf. Fig. 15) and after comparison, these curves show that PET fibres tend to have a higher lifetime than PEN fibres for maximum load ranging between 65 and $90 \%$ of breaking load. Below this load range, the tendency seems to be reversed. This kind of result could be helpful in choosing one type of polymer according to the envisaged load range. It should be noted that the fitted curves were determined considering lifetime values above 50000 cycles, as lower values may not be due to a failure provoked by the fatigue process but due to creep.

The influence of the minimum load has already been shown to be very important, and a sufficiently high minimum load could even have prevented fatigue failure or, at least, led to a lifetime so long that the experiment was stopped before failure occurred. By increasing the minimum load (or/and reducing the 
maximum load), the cyclic loading tends to a state of constant loading, which would induce creep failure. The results presented here tend to confirm this, but the constant maximum load chosen was rather high (80\%). Further experiments with a lower maximum load would most probably show the same effect of preventing fatigue, and morphologies could be helpful to determine which failure mechanism is involved.

The effect on fatigue lifetime of the maximum applied load is what would be expected : the higher the maximum load, the shorter the lifetime. Nevertheless, fracture morphologies show a more complex phenomenon : for very high maximum loads, most fibres submitted to cyclic loading show a tensile/creep morphology. The clear competition between creep failure and fatigue failure results in the former process dominating if the maximum cyclic load is greater than $80 \%$ of the monotonic tensile breaking load. Fatigue has been interpreted as occurring only for lower maximum loads for which creep failure would take sufficiently long so as to allow the fatigue process to dominate. This study has shown however that failure induced under high load conditions, which does not produce the tongue and groove type morphology, is not always identical to the usual creep failure, and often shows step by step propagation on the slow crack growth area. This is particularly noticeable in the PEN fibres but in the light of results on these latter fibres, the process has also been observed to occur in PET fibres, although it is less distinctive. Some striations were also observed on the V-crack of the final failure part of fibres presenting a fatigue fracture morphology.

The present study has revealed that there are three failure processes which can be initiated during cyclic loading. Cyclic loading to high fractions of the failure stress can result in monotonic type creep failure. Cyclic loading can also lead to failure which is superficially similar to monotonic creep failure but shows step by step crack propagation during the slow propagation phase. Finally, cyclic loading can lead to the tongue and groove type fatigue failure which has been identified before for organic fibres. The striated morphology is a typical characteristic of fatigue failure occurring in metals. However, the load range, and striations propagation process involved here are different from those usually considered in the case of metal fatigue. It is more relevant to explain the phenomena leading to these striated morphologies on fibres in the light of previous studies on amorphous and semi-crystalline polymers.

It is possible that the striations are a consequence of slow crack propagation which is arrested by the reducing applied load each cycle only to be reinitiated during the increasing load regime of the following cycle. However this would imply that this phenomenon occurs in a very narrow loading range as the number of striations is a very small fraction of the number of cycles to which the fibre has been subjected.

A theory put forward by Andrews [25] considers the stress distribution around the crack tip. The maximum stress locii form preferential paths for the crack propagation which coincide at first with the initial crack axis but then curve away to both sides. Under the usual tensile loading, the crack follows the same initial axis. Under some particular circumstances, such as "mechanical hysteresis", a shift between the crack progress and the stress state can appear during extension, so that the crack will be deviated, until relaxation restores the original stress state. This accounts for the striated morphology, and such fractographies were observed on PMMA (bulk). In more recent literature [26], Suresh differentiates fatigue striations, for which each striation is due to one loading cycle, from what he calls "discontinuous growth bands". The latter are described as sudden bursts of crack growth every hundredth cycle or so, due to an accumulation of damage ahead of the crack (sometimes called crazing) combined with shear bands. The phenomenon has been highlighted through experiments coupling observation and acoustic emission, and also resulted in a striated fracture morphology on a PVC sample.

The differences in size between the striations observed on PEN fibres from those on PET fibres might be due to the difference of molecular structures, and both theories mentioned above can easily explain their existence. Though time dependency of the phenomenon seems obvious, the exact chronology of the failure mechanism is not yet fully understood, as it must be made clear whether striations are formed each cycle, or whether they should be described as discontinuous growth bands.

The tongue and groove morphology can also be explained by the consideration of stress distribution around the crack tip : the sharp deviation is most probably due to a sudden change in the position of the maximum stress zone.

\section{Conclusion}

Polyethylene terephthalate fibres have been compared to polyethylene naphthalate fibres under tensile, creep and fatigue conditions. The fibres share many common behaviours but the higher initial modulus of the PEN fibres makes them attractive for some applications such as mooring ropes. The processes which lead to distinctive failure morphologies in other thermoplastic fibres such as PA66 and PA6 also occur in these fibres. This was known for the PET fibres but has never been studied with the PEN fibres. It has been shown that the failure of fibres subjected to cyclic loading cannot always be explained by creep processes and that the fracture morphologies associated with each type of failure process are usually very distinct. The effects of maximum cyclic load and minimum cyclic load have been seen to be similar in the two types of fibres. Whereas the effects of an increasing maximum cyclic load are to reduce lifetimes to failure, as could be intuitively expected, the effects of raising the minimum cyclic load are to lengthen lifetimes. Both the fibres considered in this study were observed to fail by a previously unnoticed process leading to step by step crack propagation normal to the fibre axis and then final catastrophic failure of the remaining cross-section. Cyclic loading has two distinct effects on fibres failure. First the lowest load ranges considered in this study can lead to a fatigue process with sharp deviation of 
the crack and propagation at a very small angle along the fibre axis. Parallel to that, many of the fibres that failed after cyclic loading, either by a fatigue process or by a creep process, showed a striated morphology on the V-crack part of the morphology, suggesting that the crack was cyclically deviated either with the same frequency as the load or more randomly. The time dependency of the phenomenon is still to be investigated through further experiments which would consider the effects of the cyclic load frequency on the failure process.

\section{Acknowledgments}

This study is part of a joint industrial project partly financially supported by the French CEP\&M. The authors would like to thank MM. Favry, Teissedre and Le Clerc for their technical and scientific support. They are grateful to Performance Fibers for supplying PEN yarns and especially M. Parguez for his cooperation and interest in this subject, and Ms Muller for her logistical help.

\section{References}

1. P. DAVIES, M. FRANÇOIS and F. GROSJEAN, in proceedings of the 2002 OffshoreTechnology Conference, Houston, Texas (2002) 14246.

2. J.F. MANDELL, M.G. STECKEL, S.-S. CHUNG and M.C. KENNEY, Polym. Eng. Sci. 27 (1987) 1121.

3. A.S. HOCKENBERGER, S. KORAL and M.A. WILDING, Text. Res. J. 75 (2005).

4. J.M. HERRERA-RAMIREZ, Ph.D. Thesis, Ecole Nationale Supérieure des Mines de Paris (2004).

5. C. OUdET, A.R. BUNSELL, R. HAGEGE and M. SOTTON, J. Appl. Polym. Sci. 29 (1984) 4363.

6. L. NASRI, A. LALLAM and A.R. BUNSELL, Text. Res. J. 71 (2001) 459.

7. A.R. BUNSELL and J.W.S. HEARLE, J. Mater. Sci. 6 (1971) 1303.

8. J.M. HERRERA-RAMIREZ and A.R. BUNSELL, J. Mater. Sci. 40 (2005) 1269.

9. A.R. BUNSELL and J.W.S. HEARLE, J. Appl. Polym. Sci. 18 (1974) 267.

10. P.L. CARR, H. ZANG and I.M. WARD, Polym. Adv. Technol. 7 (1996) 39.

11. G. WU, Q. LI and J.A. CUCULO, Polymer 41 (2000) 8139.

12. A. SUZUKI, Y. NAKAMURA and T. KUNUGI, J. Polym. Sci. B. 37 (1999) 1703.

13. A. SUZUKI, Y. NAKAMURA and T. KUNUGI, Polymer 40 (1999) 5043.

14. C.J.M. VAN DER HEUVEL and E.A. KLOP, Polymer 41 (2000) 4249.

15. A. SUZUKI, T. KUWABARA and T. KUNUGI, Polymer 39 (1998) 4235.

16. G. WU and J.A. CUCULO, Polymer 40 (1999) 1011.

17. A.R. BUNSELL, J.W.S. HEARLE and R.D. HUNTER, J. Phys. E 4 (1971) 868.

18. D.C. PREVORSEK, P.J. HARGET and R.K. SHARMA, J. Macromol. Sci. B 8 (1973) 127.
19. C. OUDET, Ph.D. Thesis, Ecole Nationale Supérieure des Mines de Paris (1986).

20. A. MARCELLAN, Ph.D. Thesis, Ecole Nationale Supérieure des Mines de Paris (2003).

21. A. MARCELLAN, A. BUNSELL, R. PIQUES and P. COLOMBAN, J. Mater. Sci. 38 (2003) 2117.

22. A. MARCELLAN, P. COLOMBAN and A. BUNSELL, J. Raman Spectrosc. 35 (2004) 308.

23. P.L. CARR, T.M. NICHOLSON and I.M. WARD, Polym. Adv. Technol. 8 (1997) 592.

24. R. JAKEWAYS, J.L. KLEIN and I.M. WARD, Polymer 37 (1996) 3761.

25. E. H. ANDREWS, in "Fracture in Polymers", (Oliver and boyd, 1968) p. 133.

26. S. SURESH, in "fatigue of materials, $2^{\text {nd }}$ edition", (Cambridge University Press, 1998) p. 411. 